\title{
Evidentials and (relayed) speech acts: Hearsay as quotation*
}

\author{
Natasha Korotkova \\ University of Tübingen
}

\begin{abstract}
This paper is devoted to what I will call quotative uses of hearsay evidentials, which report a speech act made by a third party. Occasionally mentioned in the typological literature, quotative uses were first given a formal semantic account by Faller (2002) and have received little attention since. The goal of this paper is to put the spotlight on them. An ongoing debate in the literature is on the semantic status of evidentials and the place of evidentiality among other categories (see Matthewson 2012 and references therein). For Faller (2002, 2007), quotative uses are among the empirical tests that diagnose illocutionary evidentials, ones that deal with the structure of speech acts. In this paper, I re-implement Faller's (2002) original proposal within Krifka's (2014) framework that provides an explicit syntax-pragmatics interface. I then argue that quotative readings may be the only true cases of illocutionary evidentials. I conclude by discussing quotative uses within the broader context of reported speech strategies.
\end{abstract}

Keywords: evidentiality, hearsay, speech acts, cross-linguistic variation, reported speech

\section{Introduction}

In some languages, hearsay evidentials can have what I will call quotative interpretations with questions and imperatives. Such interpretations create an effect of a relayed speech act, one where the current speaker is not asking a question or issuing a command but merely reports that such a speech act was performed by a third party.

Quotative interpretations of questions were first discussed in the formal semantic literature by Faller (2002) based on data from Cuzco Quechua (Quechuan: Peru). Consider three logically possible interpretations of the interrogative sentence in (1) containing enclitic $=s i$, which signals the speaker's hearsay in root declaratives: ${ }^{1,2}$

* For feedback and discussion, I thank Pranav Anand, Dustin Bowers, Sven Lauer, Roumi Pancheva, Yael Sharvit, Dominique Sportiche, Tim Stowell, Igor Yanovich, and the audiences at UiL OTS, Utrecht; ILLC, Amsterdam; SALT 25, Stanford; Zukunftskolleg, Konstanz; and Carnegie Mellon University, Pittsburgh. I also thank Yu Tanaka for help with Japanese.

$1=s$ is in (1) is a morphophonemic variant of $=s i$.

2 Glosses used: 1,2,3 person; ACC accusative; ADD additive; CNJ conjunct; DEF definite; DIR direct 
Evidentials and (relayed) speech acts

(1) Cuzco Quechua

Pi-ta $=\mathrm{s} \quad$ Inés-qa watuku-sqa?

who-ACC=REP Inés-TOP visit-PST

(i) SPEAKER-ORIENTED $\approx$ 'Given what I heard, who did Inés visit?' (not attested)

(ii) ADDRESSEE-ORIENTED ₹ 'Given what you heard, who did Inés visit?'

(iii) QUOTATIVE $\approx$ 'Someone said: who did Inés visit?'.

(adapted from Faller 2002: 230, ex.189b)

The interpretation in (1i), where the evidential signals the speaker's hearsay, is logically possible but is not attested across languages (see Korotkova 2016: $§ 8.3$ for discussion of putative counter-examples).

The interpretation in (1ii), where the speaker expects the addressee to base their reply on a particular type of evidence, is universally available for evidentials that can appear in questions (regardless of which information source they denote) and is frequently analyzed as an instance of perspective shift (Speas \& Tenny 2003; Lim 2010; Murray 2010, 2012; Korotkova 2016).

In this paper, I focus on (1iii). This interpretation is only available for hearsay evidentials and has been described in the literature as "anchored to the speaker" (Faller 2002; Murray 2010; Lim 2010; San Roque, Floyd \& Norcliffe 2017). While it is true that $=s i$ is in some way about the speaker's hearsay, there is an important asymmetry between (1iii) on the one hand, and (1i) \& (1ii) on the other:

- (1i) and (1ii) are speech acts of question performed by the speaker and requesting particular actions from the addressee;

- in (1iii), the current speaker is not requesting information from the addressee but merely reports a question made by a third party.

What I call quotative readings may also arise with imperatives, exemplified in (2):

(2) Mbyá (Tupi-Guaraní: Argentina, Brazil and Paraguay)

E-me'ẽ je ka'ygua chevy pe.

2.IMP-give REP mate me to

'Someone said: Give me the mate!'

(Thomas 2014: 3, ex.7)

Similar to Cuzco Quechua (1iii), in Mbyá (2) the current speaker is not requesting actions from the addressee but merely reports a command made by a third party.

evidential; ILLA illative; IMP imperative; INCL inclusive; IND indicative; INF infinitive; INSTR instrumental; LK linker; LOC locative; NEG negation; NMLZ nominalization; NOM nominative; O object; PL plural; PROG progressive; PST past; Q question; QUOT quotative; REP reportative evidential; sg singular; TOP topic. 
Quotative readings are typologically rare and are documented only for a handful of languages: (i) questions in Cuzco Quechua (Faller 2002) and Kham (Sino-Tibetan: Nepal; Aikhenvald 2004 based on data from Watters 2002); (ii) imperatives in Mbyá (Thomas 2014), Shipibo-Konibo (Panoan: Peru; Valenzuela 2003), Tagalog (Austronesian: Philippines; Schwager 2010), and Tariana (Arawak: Brazil; Aikhenvald 2004); and (iii) both questions and imperatives in Kaalallisut (Eskimo-Aleut: Greenland; Fortescue 2003; Bittner 2008). ${ }^{3}$ Perhaps due to their rarity, quotative readings have received little attention in the formal semantic literature. For Faller (2002, 2007), quotative readings in questions serve as an unmistakable diagnostic of illocutionary evidentials, ones that operate at a level higher than proposition and deal with the structure of speech acts. The availability of such readings for hearsay $=s i$ is then used as an argument for treating all evidentials in Cuzco Quechua as speech act modifiers.

Faller's seminal work is tightly connected to an ongoing debate on the place of evidentiality among other categories and its relation to epistemic modality. According to one line of research (Faller 2007; Matthewson, Davis \& Rullman 2007), evidentials within and across languages fall into two semantic classes: (i) modal, analyzed as a garden variety epistemic modals (Izvorski 1997 and later work); and (ii) illocutionary. Evidentials in Cuzco Quechua, as well as in Cheyenne (Algonquian: United States) (Murray 2010, 2014, 2016), are often regarded as typical representatives of the latter class. Another line of research (Matthewson 2012), rooted in the typological tradition (Bybee 1985 and later work), highlights concerns regarding empirical diagnostics for illocutionary evidentials and argues that all evidentials are modal.

In this paper, I concentrate on the role of quotative readings in the above debate. I agree with Faller 2007 that quotative readings provide strong evidence for illocutionary evidentials. In section 2 , I start by providing a semantics for such evidentials within Krifka's (2014) framework. Section 3 discusses the status of quotative readings among other properties of evidentials that have been used to motivate an illocutionary analysis. Section 4 puts quotative readings in the broader context of reported speech strategies. Section 5 concludes.

3 Clause types corresponding to questions and imperatives often have dedicated morphosyntax, so it is possible to check whether an evidential can appear in such clauses. Other speech acts such as assertions and exclamatives fall outside the scope of this paper for the following reasons. Given that assertions usually have no overt expression, it is hard to tell a 'quoted' assertion from a 'quoted' proposition. A good place to start might be languages with morphologically non-zero indicative mood, but such data are not readily available to me, as well as data on evidentials in exclamatives (apart from mirative interpretations, which express surprise). 
Evidentials and (relayed) speech acts

\section{Analyzing quotative readings}

Faller (2002) treats quotative readings on a par with other uses of hearsay $=s i$ and provides a unified semantics for all evidentials in Cuzco Quechua. I argue that quotative readings are exceptional and thus warrant a special account, which I formulate using Krifka's (2014) system.

\subsection{Faller 2002: Hearsay as presentation}

Under Faller's (2002) analysis, formalized within the Speech Act Theory (Searle \& Vanderveken 1985; Vanderveken 1990), Cuzco Quechua evidentials deal with the overall structure of speech acts and operate at the level of meaning higher than the proposition. This view is largely motivated by the fact that in Cuzco Quechua, evidential enclitics $=m i$ (direct), $=s i$ (hearsay) and $=c h a ́($ conjectural) take obligatory wide scope with respect to negation, tense and conditionals, and cannot occur in attitude reports or conditional antecedents. Specifically, Faller treats evidentials as functions from speech acts to speech acts that modify sincerity conditions. Sincerity conditions constitute a set SINC of mental attitudes of the speaker towards propositional content $p$ such that all $M$ in SINC should be satisfied in order for the speaker to be sincere in performing a given speech act. For example, Faller analyzes ordinary assertions as requiring that the speaker believe $p$, i.e. $\mathrm{SINC}=\{$ Believe $($ speaker,$p)\}{ }^{4}$

Direct $=m i$ and conjectural $=c h a ́$ are analyzed as adding new sincerity conditions to the speech act they modify. For example, Faller argues that $=m i$ signals best possible grounds, which includes direct perception and e.g. knowledge from an authority such as encyclopedia. An assertion with $=m i$ would then have the following sincerity conditions SINC $=\{$ Believe $($ speaker,$p), B p g($ Believe $($ speaker,$p))\}$, where Bpg stands for best possible grounds.

Hearsay $=s i$ is modelled in a different way. Faller argues that sentences with $=s i-$ regardless of the input speech act—constitute a new type of speech act: that of "presentation". A special feature of speech acts of this sort is that the usual sincerity conditions do not apply, and the only condition is that the speaker has hearsay evidence. For instance, the speaker does not need to believe $p$ if $=s i$ applies to an assertion. (3) is a generalized version of the semantics for $=s i$ :

4 Note that other views on the norms of assertion would require justified belief or knowledge (see Williamson 2000 for discussion). 
(3) Lexical entry for $=s i$

$\begin{array}{ll}\text {-si: } & \operatorname{ILL}(p) \\ & \operatorname{SINC}=\{M(s, p)\}\end{array} \begin{aligned} & \operatorname{PRESENT}(p) \\ & \operatorname{SINC}=\{\exists z(I l l(z, p) \wedge z \notin\{s, h\})\}\end{aligned}$

where $s$ is the speaker, $h$ is the hearer, and ILL is a variable over illocutionary forces, e.g. assertion, question, etc.

(Faller 2002: 234, ex.196)

In words, $=s i$ can take any speech act, of any illocutionary force ILL and with whatever sincerity conditions it has (represented as $M$ for mental attitudes), and turn it into a speech act of presentation by completely overwriting the resulting illocutionary effect and sincerity conditions.

The semantics in (3) does double-duty. First, it correctly predicts the existence of quotative readings. Because the current speaker has no stakes in the original question or command, it is possible to use $=$ si to perform secondhand speech acts. ${ }^{5}$ Second, such semantics also accounts for non-committal readings in declaratives, illustrated in (4) below:

(4) Cuzco Quechua

Pay-kuna $=\mathrm{S}$ ñoqa-man-qa qulqi-ta muntu-ntin-pi saqiy-wa-n,

mana-má riki riku-sqa-yki ni un sol-ta centavo-ta-pis

not-SURP right see-PP-2 not one sol-ACC cent-ACC-ADD

saqi-sha-wa-n-chu.

leave-PROG-10-3-NEG

'They left me a lot of money, as it is said, but, as you have seen, they didn't leave me one sol, not one cent.'

(Faller 2002: 191, ex.152)

In (4), the speaker explicitly states the scope proposition to be false. The semantics in (3) correctly predicts that such readings should be available for $=s i$. The lexical entry says that the speaker witnessed a speech act and then reproduces it without any commitment that would be usually associated with this type of speech act. For instance, in assertions, attaching $=s i$ results in a proposition $p$ that has been uttered, but there is no requirement that the speaker believe it. It is equivalent to saying that the speaker merely has hearsay evidence for $p$.

While suitable for Cuzco Quechua data, Faller's system does not account for the cross-linguistic picture. For Faller, quotative readings in questions is of the same nature as the lack of commitment in assertions. However, while quotative readings are quite rare (as mentioned in section 1), non-committal readings of

5 Under this approach it is not clear why $=s i$ cannot be used to 'quote' imperatives. 
hearsay evidentials in declaratives are widespread, if not universal (AnderBois 2014). There are many of languages that allow the latter but ban the former, e.g. Bulgarian; Cheyenne (Murray 2010); Turkish. If the two readings are derived via the same mechanism, such a discrepancy is not explained.

Furthermore, different theoretical claims taken together make wrong empirical predictions. First, quotative readings seem to require an illocutionary analysis (the view I am going to defend). Second, the prevalent perspective in the semantic literature on evidentiality (Faller 2002, 2007; Garrett 2001; Matthewson et al. 2007; Matthewson 2012; Murray 2010) is that speech act material is scopally inert and must be confined to the root level. Together, these premises imply that quotative readings and non-embeddability go hand in hand. While true for Cuzco Quechua, this is not the case universally, as discussed in detail in section 3. Therefore, it is advantageous to have a theory that separates the two properties.

Finally, as discussed in Faller (2002) and Murray (2010, 2014), there remain outstanding implementational questions for the theory. Specifically, it is not clear what the conceptual status of speech acts of presentation is and what the speaker is committed to when performing them.

Murray 2010, 2014 proposes a framework that solves this problem. In Murray's system, all speech acts involve presenting the scope proposition by introducing a discourse referent for it. Ordinary assertions include a proposal to update the common ground with $p$. Assertions with hearsay evidentials lack this component, which accounts for the non-commitment on part of the speaker.

However, Murray's system does not derive quotative readings with questions or imperatives. In that formalism, there is simply no way to introduce speech acts made by a third party while simultaneously preserving commitments of the speaker.

In this section, I have outlined Faller's (2002) analysis of quotative readings of evidentials, and discussed empirical and conceptual problems it faces. In the next two sections, I extend Krifka's system of embedded speech acts to quotative readings (Krifka 2014, 2015; Cohen \& Krifka 2014); see also Thomas 2014 for another empirical application.

\subsection{The formalism: Speech acts as option space changers}

I recast Faller's initial observations in Krifka's (2014) system, which provides a compositional semantics for the speech act layer of the clausal spine (see syntactic literature on the left periphery, e.g. Rizzi 1997; Speas \& Tenny 2003; Haegeman 2012; Sundaresan 2012). The advantage of this framework is that it gives a transparent syntax-pragmatics interface and allows to explicitly manipulate speech act material, e.g. embed it under attitudes. Unless specified otherwise, I am faithful to the version of this system proposed in Krifka 2014. 


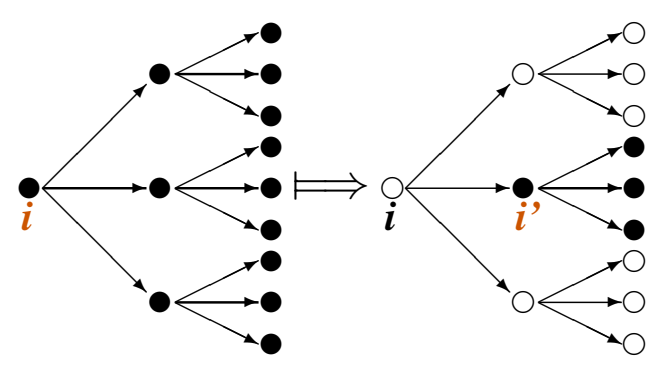

Figure 1 Index change

Krifka's system recognizes four basic types: individuals $(e)$; truth values $(t)$; indices $(s)$, and contexts $(c)$. Indices are time-world points, and contexts are triples of the form $\left\langle c_{s}, c_{a}, c_{t}\right\rangle$ where $c_{s}$ is the speaker, $c_{a}$ the addressee, and $c_{t}$ the utterance index. Domain of indices $I$ is ordered by a relation of precedence $\leq$ that is transitive, reflexive and left-linear. This generates a tree of indices where each index is the root of an option space that represents the future and is the end of a linearly ordered set of indices that represents the past.

Speech acts in this theory create commitments between interlocutors. This is recorded as the change in indices (see Figure 1 below), from index $i$ where certain commitments between interlocutors do not hold to index $i^{\prime}$ where they hold. In words, speech acts update the context so that the utterance index $c_{t}$ moves forward in its option space (following Szabolcsi 1982).

Index change is defined via index incrementation with a certain illocutionary condition $\mathrm{F}$ and is an instruction to find the closest index $i^{\prime}$ such that $i \leq i^{\prime}$ and that $F$ is true of $i{ }^{\prime}{ }^{6}$ In short:

(5) $\quad i \leq_{M I N} i^{\prime} \wedge F\left(i^{\prime}\right)$

Conditions on commitments are recorded with the help of illocutionary operators, which are defined in terms of illocutionary predicates:

- Assert for assertions

- Direct for commands

- Quest for questions

6 Time is treated as discrete for the simplicity of representation (with Thomas 2014). Nothing hinges on it so time can be treated as dense (as in Krifka 2014). 
Evidentials and (relayed) speech acts

Speech Act Potential (SAP) is an element that can be used to perform a speech act in a context and is defined as a function that maps a speaker $x$, an addressee $y$ and an index $i$ to an index $i$ ' that increments $i$ with a specific condition on commitments of $x$ and $y$.

(6) $\quad \lambda F . \lambda x . \lambda y . \lambda i . u i^{\prime} . i \leq_{M I N} i^{\prime} \wedge F(x)(y)\left(i^{\prime}\right)$, where $F$ is a variable over illocutionary predicates, $x$ is the speaker and $y$ is the addressee

A speech act is an update of the common ground with a speech act potential. Illocutionary operators head ForceP (initially proposed by Rizzi 1997). An illocutionary operator takes the meaning of an IP (e.g. propositions in the case of assertions, proposition sets in the case of questions, etc) as an argument and returns a SAP, which is further available in semantic computation. To show this in action, below I introduce illocutionary operators for assertions and questions and provide derivations for sample sentences containing those operators.

The illocutionary operator responsible for assertions is defined in (7):

(7) Semantics for the assertion operator ASSERT

a. $\llbracket$ ASSERT $\rrbracket^{c, g}=\lambda p . \lambda x . \lambda y \cdot \lambda i . \imath i^{\prime} . i \leq_{M I N} i^{\prime} \wedge \operatorname{Assert}(p)(x)(y)\left(i^{\prime}\right)$

b. $A \operatorname{ssert}(\mathrm{p})(\mathrm{x})(\mathrm{y})(\mathrm{i})$ is true iff in $i, x$ takes up assertive commitments towards $y$ with respect to $p$

(8) provides a derivation for a sample declarative sentence.

(8) A sample assertion

a. Inés came.

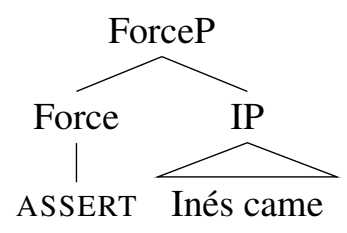

b. $\llbracket[$ ForceP [Force ASSERT $][$ IP Ines came $]] \rrbracket^{c, g}$

$$
=\lambda x . \lambda y . \lambda i . u i^{\prime} . i \leq_{M I N} i^{\prime} \wedge \operatorname{Assert}\left(\llbracket \text { Ines came } \rrbracket^{c, g}\right)(x)(y)\left(i^{\prime}\right)
$$

In a similar vein, the illocutionary operator responsible for questions is defined in (9) (following the preference semantics for questions of Condoravdi \& Lauer 2012; Lauer 2013): 
(9) Semantics for the question operator QUEST

a. $\llbracket$ Quest $\rrbracket^{c, g}=\lambda Q . \lambda x . \lambda y . \lambda i . \imath i^{\prime} . i \leq_{M I N} i^{\prime} \wedge Q u e s t(Q)(x)(y)\left(i^{\prime}\right)$

b. Quest $(\mathrm{Q})(\mathrm{x})(\mathrm{y})(\mathrm{i})$ is true iff in $i, x$ commits to a preference such that $y$ asserts one of the propositions $p$ in the answer set $\mathrm{Q}$

(10) provides a derivation for a sample interrogative sentence:

(10) A sample question

a. Who did Inés visit?

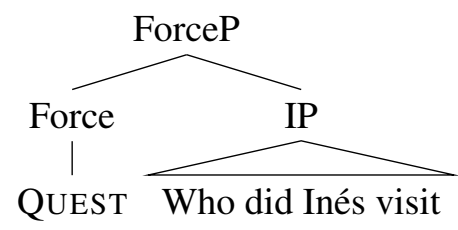

b. $\llbracket[$ ForceP $[$ Force QUEST $][$ IP Who did Ines visit $]] \rrbracket^{c, g}$

$=\lambda x . \lambda y . \lambda i . t i^{\prime} . i \leq_{M I N} i^{\prime} \wedge$ Quest $\left(\llbracket\right.$ Who did Ines visit $\left.\rrbracket^{c, g}\right)(x)(y)\left(i^{\prime}\right)$

\subsection{Proposal: Quotative readings as quotation}

My account extends the approach of Thomas (2014), who applied Krifka's (2014)'s system to embedded imperatives in Mbyá. I postulate two homophonous markers in languages like Cuzco Quechua: one that is ordinary hearsay, and another that has the quotative function. Under my analysis quotative hearsay evidentials are functions that take a speech act as one of their arguments and return the assertion that the current speaker only acknowledges the fact that a third party performed said speech act at some prior moment. Crucially, it is a secondhand speech act: the current speaker is not asking a question or issuing a command.

The semantics for the quotative reading of Cuzco Quechua $=s i$ is given in (11) below. It is a function that maps a $\operatorname{SAP} A$, a speaker $x$, an addressee $y$ and an index $i$ to an index $i^{\prime}$ that increments $i$ with an assertive commitment by $x$ towards $y$ such that $x$ witnessed a third party (neither $x$ nor $y$ ) performing $A$.

(11) The quotative $=s i$

$\llbracket \mathrm{SI}_{\mathrm{QUOT}} \rrbracket^{c, g}$

$=\lambda A . \lambda x . \lambda y . \lambda i . t i^{\prime} . i \leq_{M I N} i^{\prime} \wedge$

$\operatorname{Assert}\left(g(z) \notin\{x, y\} \wedge \exists j, j^{\prime} \leq i \wedge j^{\prime}=A(g(z))(x)(j)\right)(x)(y)(i)$,

where $A$ is a variable over SAPs, $x$ is the speaker, and $y$ the addressee 
Evidentials and (relayed) speech acts

The semantics in (11) achieves the "Someone said" effect seen in translations of sentences with quotative evidentials such as (1iii) and (2). (12) is the derivation for (1iii), repeated below as (12a). The procedure for imperatives would proceed along the same lines.

(12) Deriving 'quoted' questions

a. Cuzco Quechua

$\mathrm{Pi}-\mathrm{ta}=\mathrm{s} \quad$ Inés-qa watuku-sqa?

who-ACC=REP Inés-TOP visit-PST

'Someone said: Who did Inés visit?'

b. $\llbracket \mathrm{SI}_{\mathrm{QUOT}}[$ ForceP $[$ Force QUEST $][$ IP Who did Ines visit $]] \rrbracket^{c, g}$

$=\lambda x . \lambda y \cdot \lambda i . \quad l i^{\prime} . i \leq_{M I N} i^{\prime} \wedge$

$$
\begin{gathered}
\operatorname{Assert}\left(g(z) \notin\{x, y\} \wedge \exists j, j^{\prime} \leq i \wedge\right. \\
j^{\prime}=\imath j^{\prime} .\left(j \leq_{M I N} j^{\prime} \wedge\right.
\end{gathered}
$$

Quest $\left(\llbracket\right.$ Who did Ines visit $\left.\left.\left.\rrbracket^{c, g}\right)(g(z))(x)(j)\right)\right)(x)(y)(i)$

The semantics I advocate is reminiscent of Krifka's (2014) treatment of speech predicates, which can have a proposition-taking variant and a SAP-taking variant. In their SAP-taking variant, the function of verbs like say is to signal that a third party performed a particular speech act. The proposed semantics for the quotative $=s i$ in (11), additionally specifies the illocutionary contribution of sentences containing it. I propose that quotative readings of evidentials are inherently assertive: not only do they take a SAP argument, but also they introduce the assertion operator on top of it.

\subsection{Discussion}

The goal of this section was to provide a compositional account for quotative readings of hearsay evidentials. The proposed semantics has several empirical and conceptual advantages over Faller's (2002) original analysis. First, speech acts embedded under evidentials and other operators receive a unified treatment. Second, the system does not undergenerate and thus makes welcome cross-linguistic predictions. This is discussed in detail in the next section.

\section{Semantic status of evidentials within and across languages}

While a thorough overview of analytical options proposed for evidentials and their empirical underpinnings is beyond the scope of this paper (see Korotkova 2016 for a detailed discussion), in this section I want to highlight the importance of quotative readings in light of the debate on the semantic status of evidentials. 
Illocutionary approaches to evidentiality in individual languages - first of all, Faller 2002 on Cuzco Quechua and Murray 2010, 2014 on Cheyenne-emerged as a response to accounts of evidentials as epistemics. The latter type of approach was pioneered by Izvorski (1997) for Bulgarian (South Slavic: Bulgaria), to be later adopted and adapted for other languages.

The growing body of cross-linguistic data on evidentiality made it apparent that evidentials across (and even within) languages may vary along several dimensions, such as the ability to appear in conditional antecedents or attitudinal complements, and scope with respect to clause-mate operators. One prominent approach to the cross-linguistic variation in this domain is what I will call the dichotomy view (Faller 2007; Matthewson et al. 2007). According to it, the variation can be reduced to an underlying semantic distinction between modal evidentials and illocutionary evidentials.

In particular, it has been argued that illocutionary evidentials exhibit the following constellation of properties: they allow non-committal readings in declaratives, they allow quotative readings in questions and/or imperatives, and they are banned from attitudinal complements. This is precisely the case in Cuzco Quechua, a language that gave rise to the illocutionary view on evidentiality in the first place. However, in what follows I show that the dichotomy view ultimately fails to handle the cross-linguistic variation. Furthermore, out of the three properties above only one - the availability of quotative readings — requires an illocutionary analysis.

Quotative readings and non-committment As discussed in 2.1, hearsay $=s i$ in Cuzco Quechua allows readings where the speaker knows the scope proposition to be false, or is agnostic about its truth (see example (4)). Faller (2002) treats the lack of commitment in declaratives as 'quoted' assertions, on a par with quotative readings in questions. However, non-committal readings on the one hand, and quotative readings on the other, are unlikely to be derived via the same mechanism because there are many languages that allow the latter and disallow the former. The analysis of quotative readings I advocate does not necessarily treat non-commitment as quotation, and thus handles the data better than Faller's (2002) original analysis. Moreover, as discussed in Faller 2011 and Korotkova 2016: §2.4.2, the lack of commitment does not in fact require an exclusively illocutionary analysis.

Quotative readings and embedding under attitudes It is often argued that the (non-)embeddability marks the divide between illocutionary and modal evidentials (Garrett 2001; Faller 2002; Murray 2010; Matthewson 2012). Specifically, illocutionary evidentials are supposed to be banned from attitudinal complements. Because attitudes are expected to only take propositions-but not speech acts-as 
complements, clauses with those evidentials that operate at the same level as speech acts are not expected to appear in attitudes. According to the dichotomy view, the availability of quotative readings and the inability to appear in attitudes should be correlated. This is precisely the case in Cuzco Quechua. As discussed in Section 2, it allows quotative readings. It also bans evidentials from attitudinal complements, exemplified in (13) below:

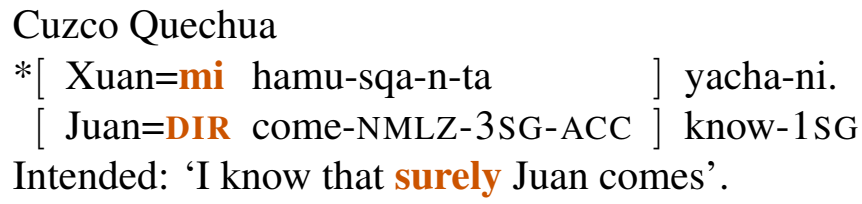

However, not all languages behave like Cuzco Quechua, which undermines the dichotomy view on evidentiality. The set of languages where quotative readings are possible is not the same as the set of languages that disallow embedding. Counterexamples go both ways: there are non-embeddable evidentials without quotative readings and there are embeddable evidentials with quotative readings.

Cheyenne is a language that disallows both syntactic embedding of evidentials and quotative readings. This is illustrated in (14) and (15) below. (14) shows that the quotative interpretation is not available for hearsay séstse in questions: ${ }^{7}$

(14) Cheyenne: questions

Tóne'še é-ho'eohtse-sèstse?

when 3-arrive-REP.3SG

\#'Someone asked: When did he arrive?'

(adapted from Murray 2010: 75, ex.3.50)

Murray (2016) (also 2010) claims that all Cheyenne evidentials are banned from subordinate structures, including both complement and adverbial clauses. (15) exemplifies the latter: ${ }^{8}$

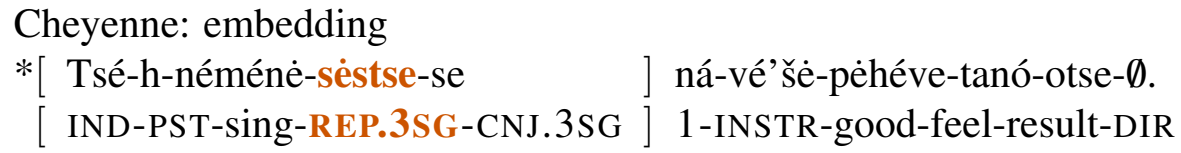

(Murray 2016: 8, ex.7a)

7 The sentence itself is well-formed and has an addressee-oriented interpretation, here irrelevant. 8 The same example without an evidential is possible (Murray 2016: 7, ex.6b). 
In contrast to Cheyenne, Tagalog is a language that allows both quotative readings (16) and embedding (17):

(16) Tagalog: quotative use of daw with an imperative

Kumain (ka) daw.

eat.INF (you) REP

'Someone said: Eat!'. ～～(adapted from Schwager 2010: 233, ex.18)

(17) Tagalog: embedding

Aalam akong [ nasa Oslo daw si Anna. ]

know I.LK [ in Oslo REP DEF.NOM Anna ]

'I know that reportedly Anna is in Oslo' (Schwager 2010: 239, ex.46b)

The discrepancy between Cheyenne and Tagalog shows that the dichotomy view does not adequately predict the cross-linguistic variation: the availability of quotative readings is not aligned with the possibility of embedding under attitudes. As such, the semantics for quotative readings proposed in 2.3 has an empirical advantage over Faller's (2002) original analysis. Because the formalism I use explicitly allows for further embedding of quotative evidentials, my analysis correctly predicts the existence of languages such as Tagalog. Moreover, as I have shown in Korotkova 2016: Ch.3, the binary distinction between embeddable vs. nonembeddable evidentials does not map onto any semantic distinctions, which is another argument in favor of an analysis of quotative readings where such readings are divorced from embedding.

I have shown that the dichotomy view makes wrong empirical predictions: it undergenerates. The actual cross-linguistic variation in evidentials is in fact not unidimensional and as such is not easily reducible to one parameter, however construed. Furthermore, the very status of empirical tests aimed at distinguishing putative modal evidentials from putative illocutionary ones is controversial. The insufficiency of those tests is the starting point of Matthewson $(2011,2012)$, a view that leans back to the typological tradition (Bybee 1985; Palmer 1986; van der Auwera \& Plungian 1998) and argues that all evidentials are just garden variety epistemic modals.

However, Matthewson does not discuss quotative readings. Such readings are easily amenable to a speech-act analysis, and thus may constitute the only valid diagnostic for illocutionary evidentials. It is therefore important to understand their status. In Section 2, I provide a formal semantics for those readings. In the next section, I outline a way to a better understanding of their pragmatics. 
Evidentials and (relayed) speech acts

\section{Reported speech strategies}

Quotative readings reproduce some previous discourse. However, the place of quotative and non-quotative uses of hearsay evidentials in the overall landscape of reported speech is unknown. Aikhenvald (2004) notes that one difference between hearsay evidentials and reported speech is that with evidentials, the source of report is often unknown. However, Kaufmann shows in Schwager 2010 that this distinction can be vague. While Tagalog daw does not require the source to be known, it may be recoverable from context or even explicitly mentioned. I propose that key to understanding quotative readings is investigating them in the broader context of reported speech mechanisms.

Reported speech has been traditionally divided into direct discourse and indirect discourse. Well-known diagnostics that distinguish between those two types (see Munro, Ludwig, Sauerland \& Fleck 2012 for an overview) include syntactic transparency, verbatim status of the report, and sensitivity to content. For example, canonical direct discourse is supposed to be opaque and ban cross-clausal dependencies, to be faithful to the form of the initial utterance, and to allow even non-linguistic content, as in Jay said: Wow!. Roughly speaking, the direct-speech strategy is compatible with just about anything, which is also notoriously hard to formalize (see Banfield 1973; Partee 1973 and later work). Canonical indirect discourse is supposed to work exactly the opposite: to be syntactically transparent, to allow non-verbatim reports, and to require that the content be linguistic, which renders Jay said that wow infelicitous.

Recent research has shown that reported speech forms a continuum. For example, in addition to, or instead of, direct and indirect discourse, a language could have various mixed strategies that allow some but not all cross-clausal dependencies (see e.g. Güldemann 2008 on reported speech in languages of the African continental mainland). One example of a mixed strategy is Free Indirect Discourse, a narrative technique used for conveying thoughts of the protagonist (see Eckardt 2014 and references therein). Furthermore, some languages have been argued to only have mixed strategies instead of the binary opposition between direct and indirect discourse, e.g. Matses (Munro et al. 2012) and Japanese (Sauerland \& Yatsushiro 2014).

The so-called quotative particles can be also viewed as a mixed strategy. For example, Japanese particles are often used as markers of direct quotation with speech verbs (18a). ${ }^{9}$ If the original sayer is recoverable from context, the matrix clause may be omitted (18b): ${ }^{10}$

9 They may also function as complementizers outside of direct quotation environments.

10 The examples in (18) use angle brackets to visualize the content of a report. I do not use square brackets to make the representation syntax-neutral. 
a. Matrix clause present:

$<$ Cheese-wa suki (ka) $>$ tte John-ga kiita.

$<$ cheese-TOP like (Q) $>$ QUOT John-NOM asked

'John told me to ask you whether you like cheese; literally: John asked:

Do you like cheese?'.

b. Matrix clause omitted:

$<$ John-ga cheese-wa suki (ka) $>$ datte.

$<$ John-NOM cheese-TOP like (Q) $>$ QUOT

'Someone said: Do you like cheese?'.

(18b) looks just like quotative uses of evidentials, and such superficial similarity warrants a detailed comparison. However, both quotative particles and quotative readings of evidentials are understudied within formal semantics and philosophy of language. In particular, it is not clear whether either of them has any properties of bona fide indirect discourse, e.g. (i) whether the report can be non-verbatim, (ii) whether indexicals must shift, (iii) whether DPs within the report can be construed 'de re'. Furthermore, quotation itself is not a homogeneous phenomenon (Capellen \& Lepore 1997, 2003, 2012; Maier 2014, 2015). Investigating those issues will advance a better understanding of quotative particles and quotative evidentials, and the potential connection between the two.

\section{Conclusion}

The paper addresses quotative uses of hearsay evidentials, where they perform secondhand speech acts. These uses are attested at least with questions and imperatives, though the two have not been previously connected in the formal semantic literature. I provide a unified way of treating them across languages in Krifka's (2014) formalism, which gives a handy system for manipulating speech act material.

It is currently a matter of debate whether speech acts should be treated with the help of dedicated semantic operators (Cohen \& Krifka 2014; Krifka 2014, 2015) or pragmatic conventions (Potts 2006; Lauer 2013). If the assumption that quotative readings embed or modify speech acts is on the right track, then the very existence of such readings constitutes a strong argument for a Krifkean view: this kind of manipulation requires an overt representation of the material being manipulated.

However, even though a speech-act treatment of quotative readings is a plausible analytical option, the semantic and pragmatic status of such readings remains unclear. The existing analyses treat 'quoted' imperatives and questions as embedded speech acts because the current speaker does not have to express a preference such that the command be fulfilled or the question be answered. However, it is not clear whether 
the speaker may have such a preference, and whether a third party to whom the initial speech act is attributed has such preference at the current moment. An active preference of this sort is what makes a speech act, and an absence thereof would indicate that quotative evidentials do not deal with communicative intentions (cf. Stegovec \& Kaufmann's (2015) discussion of imperatives under attitudes).

The semantics I propose captures the known facts. However, to fully understand the phenomenon, we need a better grasp of the empirical picture. Several further questions need to be answered:

- Why only some hearsay evidentials exhibit quotative readings?

- Why those evidentials that have quotative readings differ in whether they can take questions, imperatives, or both? Restrictions of this sort can be recorded in the proposed system via subtyping. But what is the source of those restrictions?

- What happens to other speech acts, in particular, exclamatives? Are there any languages where hearsay evidentials 'quote' exclamatives?

- Finally, what is the relation between quotative uses of evidentials and other strategies of reported speech?

\section{References}

Aikhenvald, Alexandra Y. 2004. Evidentiality. Oxford: Oxford University Press.

AnderBois, Scott. 2014. On the exceptional status of reportative evidentials. In Todd Snider, Sarah D’Antonio \& Mia Weigand (eds.), Semantics and Linguistic Theory (SALT) 24, 234-254. LSA and CLC Publications.

van der Auwera, Johan \& Vladimir Plungian. 1998. On modality's semantic map. Linguistic Typology 2(1). 79-124. doi:10.1515/lity.1998.2.1.79.

Banfield, Anne. 1973. Narrative style and the grammar of direct and indirect speech. Foundations of Language 10(1). 1-39.

Bittner, Maria. 2008. Reportative evidentials in Kalaallisut. Fieldwork notes, Rutgers. http://www.rci.rutgers.edu/ mbittner/ill08_top5.pdf.

Bybee, Joan. 1985. Morphology: A Study of the Relation between Meaning and Form. Amsterdam: John Benjamins.

Capellen, Harry \& Ernie Lepore. 1997. Varieties of quotation. Mind 106(423). 429-450. doi:10.1093/mind/106.423.429.

Capellen, Herman \& Ernest Lepore. 2003. Varieties of quotation revisited. Beligian Journal of Linguistics 17(1). 51-75. doi:10.1075/bj1.17.04cap.

Capellen, Herman \& Ernest Lepore. 2012. Quotation. In Edward N. Zalta (ed.), The Stanford Encyclopedia of Philosophy (Spring 2012 Edition), http://plato. stanford.edu/archives/spr2012/entries/quotation/. 
Cohen, Ariel \& Manfred Krifka. 2014. Superlative quantifiers and meta-speech acts. Linguistics and Philosophy 37(1). 41-90. doi:10.1007/s10988-014-9144-x.

Condoravdi, Cleo \& Sven Lauer. 2012. The basic dynamic effect of interrogative utterances. Talk presented at Texas Lingiustics Society 13, UT-Austin. http: //www.stanford.edu/ cleoc/TLS-slides.pdf.

Eckardt, Regine. 2014. The Semantics of Free Indirect Discourse: How Texts Allow Us to Mind-read and Eavesdrop. Leiden: Brill. doi:10.1163/9789004266735.

Faller, Martina. 2002. Semantics and pragmatics of evidentials in Cuzco Quechua: Stanford PhD dissertation.

Faller, Martina. 2007. Evidentiality above and below speech acts. Ms. University of Manchester. goo.gl/tzvgql.

Faller, Martina. 2011. A possible worlds semantics for Cuzco Quechua evidentials. In Nan Li \& David Lutz (eds.), Semantics and Linguistic Theory (SALT) 20, 660-683. CLC Publications.

Fortescue, Michael. 2003. Evidentiality in West Greenlandic: A case of scattered coding. In Alexandra Y. Aikhenvald \& Robert M. W. Dixon (eds.), Studies in Evidentiality, 291-306. Amsterdam: John Benjamins.

Garrett, Edward John. 2001. Evidentiality and assertion in Tibetan: UCLA PhD dissertation.

Güldemann, Tom. 2008. Quotative Indexes in African Languages: A Synchronic and Diachronic Survey. Berlin: Mouton de Gruyter.

Haegeman, Liliane. 2012. Adverbial Clauses, Main Clause Phenomena, and the Composition of the Left Periphery. Oxford: Oxford University Press.

Izvorski, Roumyana. 1997. The present perfect as an epistemic modal. In Aaron Lawson (ed.), Semantics and Linguistic Theory (SALT) 7, 222-239. CLC Publications.

Korotkova, Natalia. 2016. Heterogeneity and universality in the evidential domain: UCLA PhD dissertation.

Krifka, Manfred. 2014. Embedding illocutionary acts. In Tom Roeper \& Margaret Speas (eds.), Recursion: Complexity in Cognition, 59-88. Springer.

Krifka, Manfred. 2015. Bias in commitment space semantics: Declarative questions, negated questions, and question tags. In Sarah D'Antonio, Mary Moroney \& Carol Rose Little (eds.), Semantics and Linguistic Theory (SALT) 25, 328-345. LSA Open Journal Systems.

Lauer, Sven. 2013. Towards a dynamic pragmatics: Stanford PhD dissertation.

Lefebvre, Claire \& Pieter Muysken. 1987. Mixed Categories: Nominalizations in Quechua. Dordrecht: Kluwer Academic Publishers.

Lim, DongSik. 2010. Evidentials as interrogatives: A case study from Korean: USC $\mathrm{PhD}$ dissertation.

Maier, Emar. 2014. Pure quotation. Philosophy Compass 9(9). 615-630. 
Evidentials and (relayed) speech acts

doi:10.1111/phc3.12149.

Maier, Emar. 2015. Mixed quotation. Unpublished manuscript, Groningen. Survey article for Blackwell companion to semantics; https://db.tt/qNj1sGsg.

Matthewson, Lisa. 2011. On apparently non-modal evidentials. In Olivier Bonami \& Patricia Cabredo Hofherr (eds.), Empirical Issues in Syntax and Semantics, vol. 8, 333-357.

Matthewson, Lisa. 2012. Evidence about evidentials: Where fieldwork meets theory. In Britta Stolterfoht \& Sam Featherston (eds.), Empirical Approaches to Linguistic Theory: Studies in Meaning and Structure, 85-114. de Gruyter Mouton.

Matthewson, Lisa, Henry Davis \& Hotze Rullman. 2007. Evidentials as epistemic modals: Evidence from St'át'imcets. In Jeron van Craenenbroeck (ed.), Linguistic Variation Yearbook, vol. 7 1, 201-254. Amsterdam: John Benjamins. doi:10.1075/livy.7.07mat.

Munro, Robert, Rainer Ludwig, Uli Sauerland \& David W. Fleck. 2012. Reported speech in Matses: Perspective persistence and evidential narratives. International Journal of American Linguistics 78(1). 41-75. doi:10.1086/662637.

Murray, Sarah. 2010. Evidentiality and the structure of speech acts: Rutgers $\mathrm{PhD}$ dissertation.

Murray, Sarah. 2012. The indexical component of evidentiality. Talk given at the workshop "Meaning as Use: Indexality and Expressives" during North American Summer School on Language, Logic and Information (NASSLLI) 2012 in Austin, http://conf.ling.cornell.edu/sem/NASSLLI.pdf.

Murray, Sarah. 2014. Varieties of update. Semantics and Pragmatics 7(2). 1-53. doi:10.3765/sp.7.2.

Murray, Sarah. 2016. Evidentiality and illocutionary mood in Cheyenne. International Journal of American Linguistics 82(4). 487-517. doi:10.1086/688604.

Palmer, Frank. 1986. Mood and Modality. Cambridge: Cambridge Univeristy Press.

Partee, Barbara Hall. 1973. The syntax and semantics of quotation. In Steven Anderson \& Paul Kiparsky (eds.), A Festschrift for Morris Halle, 410-418. Holt, Rinehalt \& Winston.

Potts, Christopher. 2006. How far can pragmatic mechanisms take us? Theoretical Linguistics 32(3). 307-320. doi:10.1515/TL.2006.019.

Rizzi, Luigi. 1997. The fine structure of the left periphery. In Liliane Haegeman (ed.), Elements of Grammar, 281-337. Dordrecht: Kluwer.

San Roque, Lila, Simeon Floyd \& Elisabeth Norcliffe. 2017. Evidentiality and interrogativity. Lingua 186-187. 120-143. doi:10.1016/j.lingua.2014.11.003.

Sauerland, Uli \& Kazuko Yatsushiro. 2014. Japanese reported speech within the emerging typology of speech reports. In Shigeto Kawahara \& Mika Igarashi (eds.), Formal Approaches to Japanese Linguistics (FAJL) 7, 191-202. MIT 
Working Papers in Linguistics.

Schwager, Magdalena. 2010. On what has been said in Tagalog: Reportative daw. In Tyler Peterson \& Uli Sauerland (eds.), Evidence from Evidentials, 221-246.

Searle, John R. \& Daniel Vanderveken. 1985. Foundations of Illocutionary Logic. Cambridge: Cambridge Univeristy Press.

Speas, Margaret \& Carol Tenny. 2003. Configurational properties of point of view roles. In Anna Maria DiSciullo (ed.), Asymmetry in Grammar, 315-343. John Benjamins.

Stegovec, Adrian \& Magdalena Kaufmann. 2015. Slovenian imperatives: You can't always embed what you want! In Hedde Zeijlstra \& Eva Csipak (eds.), Sinn und Bedeutung (SuB) 19, 621-638. University of Göttingen.

Sundaresan, Sandhya. 2012. Context and (Co)reference in the syntax and its interfaces: University of Stuttgart and University of Troms $\emptyset \mathrm{PhD}$ dissertation.

Szabolcsi, Anna. 1982. Model theoretic semantics of performatives. In Ferenc Kiefer (ed.), Hungarian General Linguistics, Amsterdam: John Benjamins. doi:10.1075/1lsee.4.16sza.

Thomas, Guillaume. 2014. Embedded imperatives in Mbyá. In Hsin-Lun Huang, Ethan Poole \& Amanda Rysling (eds.), 43rd Annual Meeting of the North East Linguistic Society (NELS), 181-194. CreateSpace.

Valenzuela, Pilar M. 2003. Evidentiality in Shipibo-Konibo, with a comparative overview of the category in Panoan. In Alexandra Y. Aikhenvald \& Robert M. W. Dixon (eds.), Studies in Evidentiality, 33-62. Amsterdam: John Benjamins.

Vanderveken, Daniel. 1990. Meaning and Speech Acts, vol. 1. Principles of language use. Cambridge: Cambridge Univeristy Press.

Watters, David E. 2002. A Grammar of Kham. Cambridge: Cambridge Univeristy Press.

Williamson, Timothy. 2000. Knowledge and Its Limits. Oxford: Oxford University Press.

Natasha Korotkova

Collaborative Research Center 833 "The construction of meaning"

University of Tübingen

Nauklerstrasse 35

72074 Tübingen

Germany

n.korotkova@ucla.edu

http://nkorotkova.net 